\title{
OROFACIAL PAIN: BASIC MECHANISMS AND IMPLICATION FOR SUCCESSFUL MANAGEMENT
}

\section{DORES OROFACIAIS: MECANISMOS BÁSICOS E IMPLICAÇÕES PARA UM TRATAMENTO EFETIVO}

\author{
Paulo César Rodrigues CONTI \\ Professor, Department of Prosthodontics, Bauru School of Dentistry, University of São Paulo, Brazil.
}

\section{Richard A. PERTES}

Associate Professor of the Departament of Diagnosis Sciences, Oral Medicine, Orofacial Pain Section, University of Medicine and Dentistry of New Jersey, USA.

\section{Gary M. HEIR}

Associate Professor of the Departament of Diagnosis Sciences, Oral Medicine, Orofacial Pain Section, University of Medicine and Dentistry of New Jersey, USA.

\section{Cibele NASRI}

Member of the Orofacial Pain Group, Dental Division, Hospital das Clínicas, School of Medicine, University of São Paulo and Graduate student, Fellowship Program on “Temporomandibular Disorders and Orofacial Pain”, University of Medicine and Dentistry of New jersey.

\section{Harold V. COHEN}

Associate Professor of the Departament of Diagnosis Sciences, Oral Medicine, Orofacial Pain Section, University of Medicine and Dentistry of New Jersey, USA.

Carlos dos Reis Pereira de ARAÚJO

Professor, Department of Prosthodontics, Bauru School of Dentistry, University of São Paulo, Brazil.

$O$

rofacial Pain is the field of dentistry devoted to the diagnosis and management of chronic, complex, facial pain and oromotor disorders. This specialty in dentistry has developed over a number of years out of the need for better understanding of a group of patients who somehow were not clearly suffering from dental pain disorders, but still did not seem to have a clearly defined medical problem. After a long period of treating patients based on the mechanicist aspect of the disease, our profession has realized the importance of basic knowledge and differencial diagnosis in order to proper manage these patients. This modification in the approach has caused severe changes in education as well as in clinical activities. Historically considered as a problem of occlusion, Orofacial Pain, including Temporomandibular Disorders (TMD) has recently reached the status of "Specialty" in Brazil. Therefore, this paper aims to discuss the main differences between musculoskeletal and neuropathic pain and the importance of basic knowledge to perform successful management.

UNITERMS: Orofacial pain; Neuropathic pain; Pain transmission.

\section{INTRODUCTION}

Orofacial pain is the field of dentistry devoted to the diagnosis and management of chronic, complex, facial pain and oromotor disorders ${ }^{1,13}$ This specialty in dentistry has developed over a number of years out of the need for better understanding of a group of patients who somehow were not clearly suffering from dental pain disorders, but still did not seem to have a clearly defined medical problem ${ }^{1}$.

Orofacial pain, like pain elsewhere in the body, is usually the result of tissue damage and the activation of nociceptors, which transmit a noxious stimulus to the brain ${ }^{18}$. However, due to the rich innervation of 
the head, face and oral structures, orofacial pain entities are often very complex and can be difficult to diagnose.

Considered in the past as a "problem of occlusion", most of orofacial pain management strategies were based only on anecdotal reports. Indeed, the traditional mechanicist view of the problem has lead to extensive occlusal reconstruction treatments, with no significant results on pain. Most of recent papers has demonstrated a non-association between occlusion and orofacial pain, including Temporomandibular Disorders ${ }^{5}$. Dr. Wedden Bell has provided an enormous contribution for the fiel of Orofacial Pain. Bell gave us a road map where he defined the sources of pain as either arising from neuropathic, neurovascular or musculoskeletal disorders. He described symptoms associated with each of these systems by their location, duration, frequency, quality of pain, precipitating factors and ameliorating factors.

Ninety per cent of orofacial pain arises from the teeth and oral structures ${ }^{13}$. As dentists, we are trained to diagnose and treat often acute dental pain problems. After ruling out dental problems, musculoskeletal and neuropathic pain conditions are the most common causes of facial pain. Due to the diversity of manifestations and different mechanisms of pain transmission, the differential diagnosis is crucial for the establishment of a successful management strategy.

Based on that, the aim of this paper is to review basic concepts of pain transmission of the trigeminal system as well as to discuss differences between musculoskeletal and neuropathic pain.

\section{PAIN TRANSMISSION IN THE TRIGEMINAL SYSTEM}

Pain sensation from the intraoral and extraoral structures of the head and face are carried to the Central Nervous System (CNS) by the trigeminal system ${ }^{1,13}$. Rather than a single nerve pathway, the term "trigeminal system" refers to a complex arrangement of nerve transmission fibers, interneurons, and synaptic connections which process incoming information from the three divisions of the trigeminal nerve. The trigeminal nerve is a mixed nerve containing both sensory and motor fibers. Sensory fibers innervate the anterior part of the face, teeth, mucous membranes of the oral and nasal cavities, conjunctiva, dura mater of the brain, and intracranial and extracranial blood vessels. Motor fibers supply the muscles of mastication. Sensory information from the face and mouth (except proprioception) is carried by primary afferent neurons through the trigeminal ganglion to synapse with second order neurons in the trigeminal brain stem complex (Figure 1). While this complex receives afferent input primarily from the trigeminal nerve, it also receives afferent axons from the facial, glossopharyngeal, vagus, and the upper cervical (C2, C-3) nerves. (This connection between the upper cervical nerves and the trigeminal spinal tract nucleus may be a mechanism involved in facial pain and headaches.)

The trigeminal-brain stem sensory nuclear complex can be separated into the trigeminal main sensory nucleus and the trigeminal spinal tract nucleus, also known as the nucleus of the descending tract of cranial nerve $\mathrm{V}^{6}$.

The spinal tract nucleus is composed of three separate nuclei proceeding in a rostral (superior) to caudal (inferior) direction: subnucleus oralis, subnucleus interpolaris, and subnucleus caudalis. Subnucleus caudalis, the most caudal, is located in the medulla, at times extending to the level of $\mathrm{C} 2$ or $\mathrm{C} 3$ and is the principal brain relay site of nociceptive information arising from the orofacial region. Because the nucleus caudalis is continuous with, and structurally similar to, the spinal cord dorsal horn, and because it also extends into the medulla, it is often referred to as the medullary dorsal horn ${ }^{12}$. Both incoming nociceptive signals to the subnucleus caudalis and projecting nociceptive signals on their way to the thalamus can be modified (modulated) by descending nerve fibers from higher levels of the CNS or by drugs.

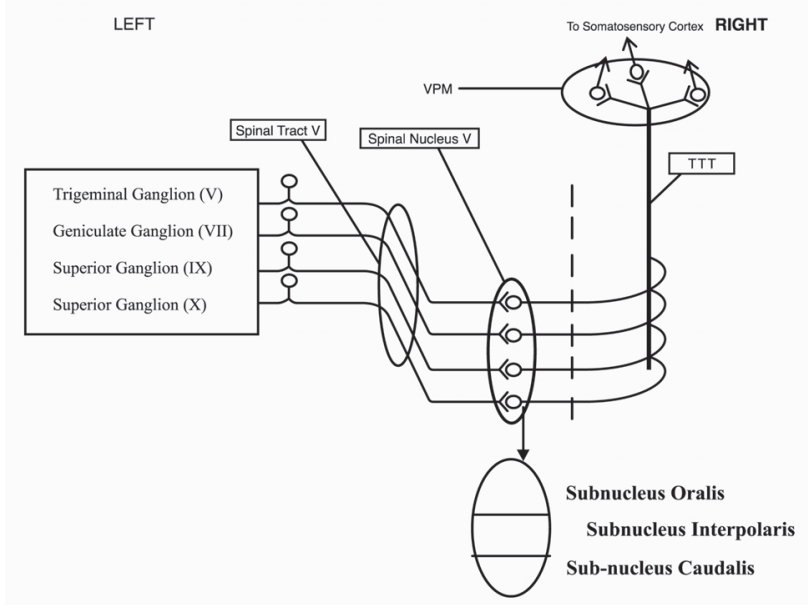

FIGURE 1 - Mechanism of Pain transmission in the trigeminal system (Adapted with permission of Dr. J. Harding, Univ. of Wisconsin) 


\section{Convergence of Neurons within the Trigeminal Spinal Tract}

Nerve fibers from different areas in the mouth may all synapse on another neuron in the spinal cord, thus sending a signal to the brain. In many cases, the brain is unable to interpret the exact location of the original oral stimulus17. A common example of this in dental practice is early pulpal pain. Pulpal tissue can be classified as "visceral tissue", in a manner similar to kidney tissue. In an inflammatory or pain process, a signal is sent only when a certain critical level of insult is reached, e.g. deep caries or an early pulpitis. This brain may appreciate that there is a toothache somewhere but cannot localize it, and, due to convergence factors, the brain may experience more difficulty in localizing the pain. Every day in general practice we hear patients say "Doc, I have a toothache but I don't know where it is".

\section{Trigeminal Second Order Neurons}

Trigeminal second order nociceptive neurons in the subnucleus caudalis can be classified into two main groups; nociceptive specific (NS) neurons and wide dynamic range (WDR) neurons. NS neurons respond exclusively to noxious stimuli such as heat and pinch. Their receptive fields are small and may include skin and muscle. WDR neurons are excited by both noxious stimuli and non-noxious tactile stimuli over a wide range of intensities. The receptive fields of WDR neurons are considerably larger than the receptive fields of NS neurons. In addition, nucleus caudalis contains low-threshold mechanoreceptors (LTM) which are activated by light tactile stimuli. These neurons have axons which form an ascending tract conducting nociceptive signals to higher levels of the brain for further processing.

\section{Third Order Neurons}

The next major synaptic connection in pain transmission is in the thalamus where axons traveling in the trigeminothalamic tract synapse with third order neurons. All sensory information from the spinal cord and brainstem passes through the thalamus making it one of the primary relay stations between the brainstem and different parts of the somatosensory cerebral cortex. For all nerve pathways from the thalamus to the cerebral cortex, there are reciprocal connections from the cortex to the thalamus. Sensory information reaching the thalamus may also be relayed to several distinct nuclei in the thalamus.
At the thalamic level, the action potential will be subjected to extensive processing through interactions among its various nuclei and by interconnections with the limbic, hypothalamic and cortical regions of the brain. It should be appreciated that until the nociceptive signal reaches the level of the thalamus, most of the reactions in the CNS have been reflex in nature. Only when the thalamus is involved, are the elements of consciousness and alertness introduced.

\section{Pain Modulation}

The human nervous system has an inherent ability to alter the intensity of nociceptive signals and reduce the pain experience. This process is called modulation. The key pathway starts in a section of the brain called the periqueductal gray region in the midbrain. Signals from this area of the brain descend to the spinal cord dorsal horn where further neuron interaction serves to reduce the transmission of the primary pain signal from the peripheral nociceptor to the second order neuron. This modulation also takes place within the spinal trigeminal nucleus.

\section{Pain Perception}

After transmission and modulation of the nociceptive signals, the final process is the perception of pain, which takes place in the posterior parietal cortex of the brain. The homunculus is a distorted human figure drawn to reflect the space our body parts occupy on the sensory cortex. The picture looks like a misshapen "little man" whose swollen lips, hands, oral cavity reflect the disproportionately large cortical areas they occupy. The differences in the size of the sensory map on the brain may reflect differences in functional importance. Thus one can see the relative importance of the oral cavity as the entrance to the digestive tract, possibly as protection.

\section{MUSCULOSKELETAL PAIN}

Musculoskeletal pain is deep, constant, dull and typically associated with a sense of tightness or pressure. It can be occasionally sharp and is increased by functional activity of the involved structures. Musculoskeletal pain can have a depressing effect in that it causes the patient to withdraw from various activities in which he or she might normally be able to participate $^{17}$

One of the most important features of musculoskeletal pain is that it is provocable and true 
to provocation. An excellent agreement has been documented for detection of TMD of muscular origin by means of palpation after a training and calibration program $^{3}$. An injured joint or muscle may be sore, painful when at rest, or it may be tender. Tenderness is pain with movement or provocation. Simply stated, an injured joint or muscle may be painful, but the pain will always increase with function of the injured structure. Just as a sprained ankle should hurt when walked on, an injured or inflamed temporomandibular joint should become more painful with mandibular movement. Therefore, one of the most important questions asked of a potential temporomandibular disorder patient is, "Does it hurt to chew?" In addition to provocability, musculoskeletal pain is also graded. The more the injured joint or muscle is moved or loaded, the greater the pain or discomfort.

The most common form of musculoskeletal pain affecting the head, neck and face is myofascial pain ${ }^{9,11}$, which is a regional pain disorder. The main characteristic of myofascial pain is the formation of myofascial trigger points (TPs). These are localized area of tender nodules in tight, palpable bands of muscle. Muscles affected by active myofascial trigger points have a reduced active range of motion. More important, when provoked, myofascial trigger points cause the referral of pain in reproducible patterns remote from the site of the trigger point. Pain intensifies with palpation of the trigger point. The area to which pain is referred is known as the zone of reference and is often distant from the involved muscle. Referred pain is not necessarily in the same dermatome. Despite this, the pattern of pain referral is reproducible, consistent and serves as a guide to locate the primary source of pain ${ }^{17}$.

A jump sign occurs with firm palpation of a trigger. This form of palpation can result in a spontaneous reaction, which includes a verbal response or report of pain from the patient and a reflexive withdrawal of the patient's head. A twitch response is the rapid, contractile motor effect elicited by "snapping palpation" of a taut band at the location of the trigger point.

The clinical implications of this knowledge are to provide the orofacial pain dental specialist with the tools to best detect the source of pain. Musculoskeletal pain, this deep, dull, aching and provocable pain is not always perceived at its source. More frequent than not, the source of the pain and the site where pain is felt are not the same. Knowledge of how to palpate for a myofascial trigger points and cause it to reproduce and refer pain is of great importance in establishing a diagnosis. Of equal importance is a recognition of the referral patterns; the zones of reference. When a patient presents with deep, dull and aching pain, know the source of the active trigger point most likely to refer to the distribution of pain also helps to go to the point of pain directly.

Treatment is more successful with a clear diagnosis.

\section{Treatment}

The approach to treatment of musculoskeletal pain should address the specific symptoms and clinical findings in each case. Several therapies, including analgesics, antiinflammatory and adjuvant medications, physical therapy and anesthetic block have been proposed for the treatment of myofascial pain.

The use of analgesic and anti-inflammatory medications is the first therapeutic step. They are efficient for acute pain control and may aid with physical therapy; however, chronic use is not indicated.

Peripheral muscle relaxants are less effective then are central agents. Centrally acting muscle relaxants with good efficacy are cyclobenzaprine and tizanadine. Tricyclic antidepressants such as amitriptyline, chlorimipramine and nortriptyline act as serotonin reuptake inhibitors and aid with pain modulation and sleep patterns ${ }^{20}$.

Benzodiazepines such as alprazolam, cloxazolam and clonazepam are effective when taken with non steroidal antiinflammatory drugs (NSAIDs) for treating acute muscle pain.

The goal of physical therapy is the inactivation of myofascial trigger points, muscles relaxation, muscle rehabilitation, and postural education. In addition, identification, assessment and elimination of contributing and perpetuating factors are vital ${ }^{21}$.

There are several effective physical therapy techniques useful in treating muscle dysfunction and pain. They include superficial heat (warm-wet), deep heat (ultrasound), cryotherapy (ice pack, vapocoolant spray) and electrotherapy (electrical stimulation (TENS). These modalities reduce muscle tension, decrease inflammation and inactivate myofascial trigger points. In complex and chronic cases, physical therapy alone may not be satisfactory, or when physical therapy is not effective or the intensity of the pain is too high, trigger point injections may be necessary. Done with either a dry needle technique or by infiltration with local anesthetic, myofascial trigger point injections can reduce pain, improve the mandibular range of motion, improve the tolerance to exercise and improve the microcirculation at the affected area. Pain relief can last from as little as 
several hours or for several months ${ }^{20}$.

The medication of choice for myofascial trigger point injection therapy is lidocaine $0.5 \%$ to $1 \%$ without vasoconstrictors. After the injection, the muscle should be progressive stretched to reestablish a normal mandibular motion. In addition, some success has been reported in treating myofascial pain with intramuscular Botox injections?. This technique promises to be of some use in the future, but does not yet have clear scientific support.

Myofascial trigger points inactivation by itself provides temporary decrease of symptoms. Rehabilitation exercises decrease the possibility of reactivation of the TPs. The goal of muscle reeducation is to control aggravating and perpetuating factors. Therefore, long-term therapy includes not only the treatment of the myofascial trigger points, but also the identification and elimination of contributing and perpetuating factors ${ }^{21}$.

An accurate evaluation to assess if symptoms are independent or secondary manifestation of a systemic disease is mandatory. Patients with systemic diseases such as fibromyalgia or rheumatologic disorders are more likely to present with pain or to maintain pain as a result of these perpetuating factors ${ }^{16}$.

The institution of good habits such as a balanced diet, restorative sleep, regular physical activities, relaxation and decrease of psychological and physical stress factors is vital to the prevention of a reoccurrence of symptoms. The psychosomatic approach includes relaxation techniques such as biofeedback, supportive psychotherapy and pharmacotherapeutics when indicated for anxiety or depression.

The treatment of musculoskeletal pain can be difficult in chronic cases. However, an accurate diagnosis, elimination of contributing factors, necessary pharmacotherapeutics, physical therapy and patient compliance can lead to successful management. Conti et $\mathrm{al}^{4}$ have demonstrated a decrease of about $50 \%$ in pain severity of chronic TMD patients, in spite of the type of pain measurement or type of treatment.

\section{NEUROPATHIC PAIN}

Neuropathic pain is one of the most challenging and complex pain conditions. It results from an abnormality in one or more components of the nervous system: peripheral, central or autonomic. These disorders comprise a group of subtypes precipitated by neural injury or disease that can result in a neuropathic pain problem, abnormal sensation or a sensory deficit. Neuropathic pain does not require the presence of a noxious stimulus in contrast to somatic pain, which does. As stated above, a noxious stimulus (excessive heat, cold and pressure, chemical) either causes tissue damage or has the potential to do so.

These pain manifestations are usually maintained by changes in the trigeminal brain stem complex known as central neuroplasticity ${ }^{2}$. When central neuroplasticity is prolonged, the result is a state of chronic or pathophysiologic pain. Because pathophysiologic pain always involves the nervous system, the terms pathophysiologic pain and neuropathic pain are used interchangeably.

An important effect of central neuroplasticity is hyperexcitability of second-order neurons in the trigeminal brain stem known as central sensitization ${ }^{14}$. Clinical consequences of central sensitization include pain in response to a non-noxious stimulus (allodynia), increased pain to a noxious stimulus (hyperalgesia) and spreading of the pain. Other peripheral neural mechanisms such as neurogenic inflammation can also contribute to pathophysiologic pain ${ }^{13,14}$. It is believed that ongoing, sustained nociceptive activity may lead to central neuroplasticity.

General characteristics of neuropathic pain include:

1. Pain in the absence of obvious nociception (i.e., detection of noxious stimuli);

2. Pain that can be intense and out of proportion to the degree of stimulation;

3. Pain quality that is bright, stimulating and burning;

4. Pain that is relatively unresponsive to low doses of narcotic analgesics.

Neuropathic pain is divided into episodic and continuous disorders. The episodic disorders are characterized by periods of total remission between episodes of paroxysmal pain. In contrast, the continuous neuropathic disorders have constant unremitting pain of varying levels of intensity without any periods of total remission. The most common episodic neuralgia affecting the orofacial region is trigeminal neuralgia; atypical odontalgia $(\mathrm{AO})$ is a prime example of a continuous neuropathic pain disorder.

A history of a toothache refractory to any nature of treatment is the common complaint of the atypical odontalgia patient. Unfortunately, information about the existence of these conditions is very reduced among general practitioners and more and more invasive procedures ( endodontic treatment, surgeries) has still been recommended to alleviate the pain.

It is crucial, therefore, to understand the process involved in $\mathrm{AO}$ and elect the better management other 
than traditional dental pain therapy.

The most likely mechanism involved in AO is related to deafferentation following injury to a nerve. In fact, several clinicians now prefer to use the term trigeminal deafferentation pain instead of atypical odontalgia.

Deafferentation is the partial or total loss of an afferent nerve supply from a particular area ${ }^{13,19}$. Trauma to a nerve commonly follows dental procedures involving the dentin, pulp or periodontal tissues. In most patients, the nerve damage is reversible within a short time. However, in a small percentage of patients (less than 3\%) who have undergone a dental procedure, pain will persist even after healing has apparently occurred. Interestingly, the pain may not appear for weeks, months or even a year after the procedure. Why pain occurs in some patients after deafferentation is not known. It has been hypothesized that perhaps there is a genetic predisposition in these patients ${ }^{8,10}$.

Involvement of the sympathetic nervous system (SMP) in AO has also been suggested, based on the reported improvement in symptoms in some patients following a stellate ganglion block ${ }^{8}$. However, more studies are needed to show the role of SMP in AO.

The management of $\mathrm{AO}$ is extremely difficult and no single approach has proven to be universally effective. AO is a chronic disorder that perplexes and frustrates both the patient and the clinician. Once AO has been diagnosed, the earlier the intervention, the better the prognosis. Of course, any dental treatment such as endodontic treatment, apicoectomy, extraction and selective tooth grinding is contraindicated. The most widely used approaches for treatment of $\mathrm{AO}$ are pharmacotherapy (tricyclic antidepressants ${ }^{15}$ and membrane stabilizers) and topical applications ( capsaicin). If sympathetic involvement is suspected, clonidine, an alpha-2- adrenergic agonist, can be added to the formulation. This drug acts to decrease the release of norepinephrine from presynaptic sympathetic terminals.

As could be seen, different mechanisms can produce similar clinical expressions. This fact strengtens the need for a differential diagnosis based on the knowledge of concepts of pain transmission. The concept of "Evidence Based Dentistry" must always guide clinical procedures, especially in a field where invasive and irreversible procedures with poor scientific evidence historically comprised standard management strategies. In other words, when performing treatments like occlusal therapies and full mouth rehabilitation, skillful professionals might be doing the "thing right", but, since pain management is the main issue, they are not doing the "right thing".

\section{RESUMO}

Dor Orofacial é um campo da odontologia dedicado ao diagnóstico e tratamento de dores orofaciais crônicas e complexas, além d e desordens motoras. Essa especialidade odontológica tem se desenvolvido por vários anos com o objetivo de prover um melhor entendimento de um grupo de pacientes que, de alguma forma, não tinham dores de origem dentária e nem condições óbvias médicas que explicassem suas dores na face. Depois de um longo período propondo tratamentos baseados apenas no aspecto mecanicista da doença, nossa profissão percebeu a importância de entender mecanismos básicos de diagnóstico diferencial para melhor controlar esses casos. Essa mudança de mentalidade tem levado a modificações na educação em odontologia, assim como nos procedimentos clínicos executados. Historicamente considerada como um "problema de oclusão", as dores orofaciais obtiveram recentemente o reconhecimento como especialidade em nosso país. Baseado nisso, o objetivo desse artigo é discutir diferenças básicas entre os tipos mais comuns de dor orofacial, assim como ressaltar a importância do conhecimento de mecanismos de condução de dor para a formulação de um plano de tratamento efetivo.

UNITERMOS: Dor orofacial; Dor muscular; Neuropatia.

\section{REFERENCES}

1- American Academy of Orofacial Pain. The scope of TMD/ orofacial pain (head and neck pain management) in contemporary dental practice. Dental Practice Act Committee of the American Academy of Orofacial Pain. J Orofac Pain 1997; 11(1):78-83.

2- Coderre TJ, Katz J, Vaccarino AL, and Melzack R. Contributions of central neuroplasticity to pathological pain: review of clinical and experimental evidence. Pain 1993; 52:259-85.

3- Conti P C R, Santos C N, Lauris J R P. Interexaminer agreement for muscle palpation procedures: the efficacy of a calibration program. J Craniomand Practice 2002; 20(4):289-94.

4- Conti P C R, Azevedo L R, Souza N V W, Ferreira F V. Pain measurement in TMD: evaluation of precision and sensitivity of different scales. J. Oral Rehab 2001; 28 (6):534-9.

5- Conti P C R, Ferreira P M, Pegoraro L F, Salvador M C G, Conti, JVC A cross-sectional study of prevalence and etiology of signs and symptoms of Temporomandibular Disorders in High School and university students. J Orofac Pain 1996; 10 (3):25462. 
6- Cooper BY, Sessle BJ. Anatomy, physiology and pathophysiology of trigeminal system paresthesias and dysesthesias. Oral Maxillofac Surg Clin N Amer 1992; 4 (2):297322.

7- Freund B, Schwartz, M, Symington JM The use of botulinum toxin for the treatment of temoporomandibular disorders: preliminary findings. J Oral Maxillofac Surg 1999; 57:916-20.

8- Graff-Radford SB, Solberg WK. Atypical odontalgia. J Craniomand Disord Oral Facial Pain 1992; 6:260-6.

9- Graff-Radford SB, Regional myofascial pain syndrome and headache: principles of diagnosis and management. Current Pain \& Headache Reports 2001; 5(4):376-81.

10- Marbach JJ. Is phantom tooth pain a deafferentation (neuropathic) syndrome? Part I. Evidence derived from pathophysiology and treatment. Oral Surg Oral Med Oral Pathol 1993; 75:95-105.

11- Mense S, Simons D. Muscle pain. Philadelphia: Lippincott Williams \& Wilkins; 2001.

12- Merrill RL. Orofacial pain mechanisms and their clinical application. Dent Clin N Amer 1997; 41:167-188.

13.- Okeson JP. Bell's orofacial pain. 5. ed. Chicago: Quintessence; 1995.

14- Ren K, Dubner R. Central nervous system plasticity and persistent pain. J Orofac Pain 1999; 13:155-163.

15- Sindrup SH, Jensen TS. Antidepressants in the treatment of neuropathic pain. In: Hansson PT, Fields HL, Hill RG, Marchettini P (eds). Neuropathic pain: pathophysiology and treatment. Seattle: IASP Press; 2001. p.169-83.

16- Siqueira, JTT. Dor orofacial. In: Teixeira MJ, Figueiró JAB. Dor: epidemiologia, fisiopatologia, avaliação. Síndromes dolorosas e tratamento. São Paulo: Grupo Editorial Moreira Junior; 2001. p.297-300.

17- Travell J, Simons D, Myofascial pain and dysfunction. Philadelphia : Williams \& Wilkins, 1983.

18- Vickers ER. Cousins MJ. Neuropathic orofacial pain part 1prevalence and pathophysiology. Aust Endod J 2000, 26(1):1926.

19- Woolf CJ, Mannion RJ. Neuropathic pain: aetiology, symptoms. Mechanisms and management. Lancet 1999; 353: 1959-64.

20- Yeng LY, Kaziyama HH, Teixera MJ. Síndrome dolorosa miofascial e Fibromialgia. In: Siqueira JTT, Teixeira M J. Dor orofacial, diagnóstico, terapêutica e qualidade de vida. Curitiba: Editora Maio; 2001. p.405-30.

21- Yeng LY, Kaziyama HH, Teixeira MJ. Síndrome dolorosa miofascial. In: Teixeira, M J, Figueiró J A B. Dor: epidemiologia, fisiopatologia, avaliação. Síndromes dolorosas e tratamento. São Paulo: Grupo Editorial Moreira Junior,. 2001. p.69-77.
Endereço para correspondência:

Faculdade de Odontologia de Bauru -USP

Departamnto de Prótese

Al. Octávio Pinheiro Brisolla, 9-75.

170012-901 BAURU S.P. 